\title{
PROGRESS OF BIOMATERIALS IN THE FIELD OF ORTHOPAEDICS
}

\author{
Chandramohan, D., J. Bharanichandar, P. Karthikeyan, R. Vijayan and B. Murali \\ Department of Mechanical Engineering, Vel Tech, Avadi, Tamilnadu, India
}

Received 2013-11-21; Revised 2013-11-21; Accepted 2014-02-06

\begin{abstract}
The aim of this study is to compare the metallic and natural fiber reinforced polymer composite bone plates used in humerus fractures. A 3D finite element model was developed to analyze the performance of both types of plates. This study proposed on fabrication of natural fiber powdered material (like Sisal (Agave sisalana), Banana (Musa sapientum) and Roselle (Hibiscus sabdariffa)) Reinforced Polymer (NFRP) composite plate material with bio epoxy resin. Instead of orthopaedics alloys such as titanium, cobalt chrome, stainless steel and zirconium, this plate material can be used for both internal and external fixation on human body for fractured bone. In this study, flexural rigidity of Sisal and banana (hybrid), Roselle and banana (hybrid) and Roselle and sisal (hybrid) composite at dry and wet conditions was studied. In this study the composition of the microstructure of composites specimens were studied using Electron Dispersive X-Ray Thermo detector and Scanning Electron Microscope.
\end{abstract}

Keywords: Natural Fibers, Material Properties, ANSYS, SEM, EDX

\section{INTRODUCTION}

Nowadays, the natural fibers such as Sisal, Banana and Roselle have the potential to be used as a replacement for glass or other traditional reinforcement materials in composites (Abrao et al., 2006). Other advantages include low density, high toughness, comparable specific strength properties, reduction in tool wear, ease of separation, decreased energy of fabrication. Composites are materials that comprise strong load carrying material (known as reinforcement) imbedded in weaker material (known as matrix). Reinforcement provides strength and rigidity, helping to support structural load (Boeree et al., 1993). The matrix, or binder (organic or in-organic) maintains the position and orientation of the reinforcement (Joseph et al., 1999). They have high specific properties such as stiffness, impact resistance, flexibility and modulus. In addition, they are available in large amounts and are renewable and biodegradable. Other desirable properties include low cost, low density. Uses of these fibers satisfy both economic and ecological interests (Blazewicz et al., 2007). The results showed that the highest mechanical properties were observed when Roselle and sisal (hybrid) fibers were incorporated. It is well understood now that both the strength and stiffness of fiber composites depend on fiber concentration, fiber aspect ratios, fiber-matrix adhesion, as well as powdered particles of fiber orientation and dispersion. The present contribution reports utilization of untreated Sisal, Banana and Roselle fibers as reinforcing fillers for bio epoxy resin Grade 3554A and Hardener 3554B as matrix for the first time (Chandramohan et al., 2010). The Roselle and sisal (hybrid) Sisal and banana (hybrid) and Roselle and banana (hybrid) fiber-reinforced polymer composites were prepared using hand molding method. The effects of fibers content on mechanical properties such as, tensile and hardness of the composites were investigated and reported. The present research work concentrates on the progress of biomaterials in the field of orthopedics, an effort to utilize the advantages offered by renewable resources for the development of biocomposite materials based on biopolymers and natural fibers. The present research work focuses on the enhanced properties of natural fiber as bone implant. It is a challenge to the creation of better materials for the improvement of quality of life. The present research work proposes suggestions of using natural fiber-reinforced composite as a plate material, which uses pure natural fibers that are rich in medicinal properties like Corresponding Author: Chandramohan, D., Department of Mechanical Engineering, Vel Tech, Avadi, Tamilnadu, India 
Sisal (Agave sisalana), Banana (Musa sapientum) and Roselle (Hibiscus sabdariffa) fibers. In the present research work, the variation of mechanical properties such as tensile, flexural and impact strengths of Sisal and banana (hybrid) at a ratio of 1:1, Roselle and banana (hybrid) at a ratio of $1: 1$ and Roselle and sisal (hybrid) at a ratio of $1: 1$ composite at dry and wet conditions was studied. In the present research work, the experimental results are compared with theoretical results and found to be in good agreement. In this present research work, microstructure of the specimens was scanned by the scanning electron microscope and composition is analyzed by the electron dispersive thermodetector.

\section{MATERIALS AND METHODS}

\subsection{Natural Fibers}

Natural fibers present important advantages such as: Low density, appropriate stiffness and mechanical properties and high disposability and renewability. Moreover, they are recyclable and biodegradable. Over the last decade, composites of polymers reinforced by natural fibers have received increased attention. Natural fibers such as sisal and roselle possess good reinforcing capability when properly compounded with polymers.

\subsection{Moisture Absorption Test Procedure}

Flexural specimens as per ASTM standards were cut from the fabricated plate. Edges of the samples were sealed with polyester resin and subjected to moisture absorption. The composite specimens to be used for moisture absorption test were first dried in an air oven at $50^{\circ} \mathrm{C}$. Then these conditioned composite specimens were immersed in distilled water at $30^{\circ} \mathrm{C}$ for about 5 days (Clemons and Caulfield, 1994). At regular intervals, the specimens were removed from water and wiped with filter paper to remove surface water and weighed with digital balance of $0.01 \mathrm{mg}$ resolution. The samples were immersed in water to permit the continuation of sorption until saturation limit was reached. The weighing was done within $30 \mathrm{~s}$, in order to avoid the error due to evaporation. The test was carried out according to ASTM D570 to find out the swelling of specimen. After 5 days, the test specimens were again taken out of the water bath and weighed (Chandramohan and Marimuthu, 2011).

\subsection{Flexural Test}

Flexural test is also known as bending test. Applying a point load at centre of composite material does it. The flexural tests were performed on the universal testing machine, using the 3-point bending fixture according to ASTMD790 with the cross-head speed of $2 \mathrm{~mm} \mathrm{~min}^{-1}$.

\subsection{Finite Element Analysis}

Analysis package using for Stress Analysis on Humeral Shaft along with plate: ANSYS 11.0 Element types used in the finite element model were SOLID92 and SHELL99. SOLID92 was used in case of metallic bone plates while SHELL99 was chosen in case of composites. Metallic plate materials were taken as isotropic, NFRP composites and the fractured bone as orthotropic materials (Baixauli, 1995) Computerized Tomography scanning image (CT scan) of humerus bone in. STL file was converted in to iges file then imported to ANSYS for the stress analysis on humeral shaft with plate and without plate.

Dimensions of plate:

Length of the plate (1): $150 \mathrm{~mm}$ Thickness of the plate $(\mathrm{t}): 4.5 \mathrm{~mm}$ Width of the plate $(\mathrm{w}): \quad 10 \mathrm{~mm}$

\subsection{Manual Calculation}

The project case is mainly for youngsters during the bike riding:

- Assumption made

- Mass of human body $=60 \mathrm{~kg}$

- Initial velocity of Vehicle $\mathrm{V}_{1}$ is $60 \mathrm{kmph}$

- Final velocity of Vehicle $V_{2}$ is zero

- Mass of human body $=60 \mathrm{~kg}$

- External diameter of bone [D] $=22 \mathrm{~mm}$

- Internal diameter $[\mathrm{d}]=11 \mathrm{~mm}$

Bending Stress on Solid Shaft:

$\sigma \mathrm{b}_{\max }=\left(32 \times \mathrm{M}_{\max }\right) /\left(3.14 \times \mathrm{d}^{3}\right)$

$\sigma \mathrm{b}_{\max }=$ Maximum bending stress in $\mathrm{N} / \mathrm{mm}^{2}$

$\mathrm{M}_{\max }=$ Maximum bending moment in $\mathrm{N} \mathrm{mm}$

\subsection{Scanning Electron Microscopy (SEM)}

A scanning electron microscopy machine Model Hitachi S-3000N was used to study the effect of the microstructure of composites specimens with moisture and without moisture. The fractographic Studies were carried out in detail on the flexural fracture surfaces of hybrid composites.

\section{DISCUSSION}

The matrix material used in this investigation was bio epoxy resin Grade 3554A and Hardner 3554B. Supplied by Lab chemicals, Chennai. Roselle, banana and sisal fibers have been used traditionally in high strength ropes in India especially in South India regions as shown in Table $\mathbf{1}$ and from the previous literature survey properties of biomaterials and mechanical properties of composites (hybrid) are shown in Table 2. 
Table 1. Materials

\begin{tabular}{lll}
\hline Material & Type & Supplied by \\
\hline Matrix & Bio epoxy resin Grade 3554A & \\
Catalyst & Hardner Grade 3554B & \\
Releasing agent & Poly vinyl acetate & Lab chemicals, Chennai \\
Reinforcement & Particle natural fibers & India especially in South India regions \\
Sisal and Roselle (hybrid) & & \\
Banana and Sisal (hybrid) & & \\
Banana and Roselle (hybrid) & & \\
\hline
\end{tabular}

Table 2. Properties of bio-materials

\begin{tabular}{lllll}
\hline Bio-Materials & Young's modulus N/mm & Density Kg/mm & Poisson ratio & References \\
\hline Humerus bone & $17.2 \times 10^{3}$ & $1.9 \times 10^{-6}$ & 0.30 & Fenner (1996) \\
Titanium & $120 \times 10^{3}$ & $4.51 \times 10^{-6}$ & 0.34 & Navarro (2008) \\
Stainless steel & $200 \times 10^{3}$ & $8 \times 10^{-6}$ & 0.20 & Ganesh $(2005)$ \\
Cobaltm chroe & $230 \times 10^{3}$ & $8.5 \times 10^{-6}$ & 0.30 & Charvet $(2000)$ \\
Zirconium & $200 \times 10^{3}$ & $6.1 \times 10^{-6}$ & 0.30 & Ramakrishna (2004) \\
Roselle and sisal (hybrid) & 18857.08 & $1.450 \times 10^{-6}$ & 0.33 & \\
Roselle and banana (hybrid) & 22061.96 & $1.5 \times 10^{-6}$ & 0.32 & Experimental results \\
Sisal and banana (hybrid) & 25779.25 & $1.350 \times 10^{-6}$ & 0.30 & (Flexural test) \\
\hline
\end{tabular}

Table 3. Comparison of manual and ANSYS results

\begin{tabular}{lll}
\hline Material & Manual $\left(\mathrm{N} / \mathrm{mm}^{2}\right)$ & ANSYS $\left(\mathrm{N} / \mathrm{mm}^{2}\right)$ \\
\hline Bone & 55.320 & 65.709 \\
Stainless steel & 60.370 & 70.953 \\
Cobalt chrome & 63.460 & 73.124 \\
Titanium & 68.560 & 77.221 \\
Zirconium & 65.480 & 75.973 \\
Roselle and sisal (hybrid) & 65.032 & 74.111 \\
Sisal and banana (hybrid) & 65.010 & 72.233 \\
Roselle and banana (hybrid) & 65.014 & 73.523 \\
\hline
\end{tabular}

The morphological data of the humerus bone was collected using the CT scanner. The humerus scanning data and model. STL manipulation were processed using MIMICS and Magics RP Software. This software can generate both the frontal and lateral view from the CT scans. The software allows isolation of humerus bone segments and hence, the transferred of STL data to CAD. Computerized Tomography scanning image (CT scan) of humerus bone in STL file was converted in to iges file then imported to ANSYS for the stress analysis on humeral shaft with plate and without plate. Bone/plate system was modelled as it was only subjected to bending stress, i.e., the case of torsion was excluded.

Friction between the plate/bone and the screw/bone interfaces were omitted. Instead, a $0.1 \mathrm{~mm}$ gap was assumed between the plate and the bone, considering that the plate would not be able to cover the whole bone surface under it as the plate/bone interface is not a smooth surface. Also, the screws were assumed to be bonded to the bone and the plate separately.

This was done by using VGLUE command to glue screw volumes to the bone volume and the plate volume separately. SOLID 186 Structural Solid is well suited to modeling irregular meshes (such as those produced by various CAD/CAM systems). The element may have any spatial orientation. SOLID 186 is a higher order 3-D 20-node solid element that exhibits quadratic displacement behavior.

The element is defined by 20 nodes having three degrees of freedom per node: Translations in the nodal $x, y$ and $\mathrm{z}$ directions. The element supports plasticity, hyper 
elasticity, creep, stress stiffening, large deflection and large strain capabilities. It also has mixed formulation capability for simulating deformations of nearly incompressible elastoplastic materials and fully incompressible hyper elastic materials. SOLID92 and SHELL99 is used for the 3$\mathrm{D}$ modeling of solid structures. The element is defined by eight nodes having three degrees of freedom at each node: Translations in the nodal $\mathrm{x}, \mathrm{y}$ and $\mathrm{z}$ directions.

The stress analysis of humerus bone and fixation of plate for the fractured bone has been carried out with titanium alloy and Roselle and sisal (hybrid), Sisal and banana (hybrid) and Roselle and banana (hybrid). After plate fixation, the stress induced on the bone with plate and without plate is calculated both manually and using ANSYS software. The stress values for the Titanium, Roselle and sisal (hybrid), Sisal and banana (hybrid) and Roselle and banana (hybrid) obtained through manual calculation were $65.56 \mathrm{~N} / \mathrm{mm}^{2}, 65.032 \mathrm{~N} / \mathrm{mm}^{2}, 65.010$ $\mathrm{N} / \mathrm{mm}^{2}$ and $65.014 \mathrm{~N} / \mathrm{mm}^{2}$ respectively. The stress values for the above metals using Ansys software were obtained as $75.221 \mathrm{~N} / \mathrm{mm}^{2}, \quad 73.111 \mathrm{~N} / \mathrm{mm}^{2}, \quad 73.233 \quad \mathrm{~N} / \mathrm{mm}^{2}$ and $73.523 \mathrm{~N} / \mathrm{mm}^{2}$ respectively as shown in Table 3. Although titanium alloy has high strength, when compared to other materials, the problems associated with its use include: Metal incompatibility, corrosion, magnetism effect, anodecathode reactions, decrease in bone mass (osteopenia), increase in bone porosity (osteoporosis) and delay in fracture healing (callus formation, ossification). Thus, with the development of Biocomposite materials, an increase in bone density is promoted due to a more suitable environment for bone growth due to the high resistance to corrosion of biopolymers and natural fibers. Fracture healing can be faster with the Natural Fiber Reinforced Polymer Composite bone plates. So this research muscularly gives confidence to utilize the advantages offered by renewable resources and its application in the field of orthopaedics for bone graft substitutes.

\section{SEM MICROGRAPH OF FIBERS UNDER FLEXURAL LOADING}

Both in the banana and sisal fibre composites, the percentage elongation are found to be increasing in wet condition (Fig. 1a). The reason could be the presence of water attack on the cellulose structure, allowing the cellulose molecules to move smoothly. Hence, for the applications where flexural loading conditions are dominating, sisal and banana hybrid composites could be selected. There is less fiber pull out and more interfacial adhesion. In addition to fiber pull out as the mode of fracture, fiber breakage can also occur. This is an evidence of effective stress transfer between fiber and matrix (Fig. 1b).

It shows that due to fiber pull-out voids are formed in between surface, due to the point load. River patterns are seen adjacent to the crack growth near the fiber pull-out region. The presence of river patterns is seen on the larger part of the resin-rich region; it is possible to discern some indication of the crack growth direction. The fibers are not bonded with the resin, leading to the conclusion that the fiber-matrix interface was weak (Fig. 1c). Cellulose is a hydrophilic polymer, which is capable of forming hydrogen bonds with water molecules because of hydroxyl group in its chemical structure. When incorporated into polymer matrix, cellulose is still capable of absorbing water (Fig. 2a). Water penetrates into interface between polymer and cellulose that decreases interfacial adhesion between fiber and matrix. This phenomenon has a great negative impact on mechanical properties of composites (Fig. 2b) and Fig. $\mathbf{2 c}$ shows effect of loading on water sorption of composites. It is clearly seen that water sorption increases with increasing hydrophilicity of the composite as expected.

\subsection{Flexural Test}

The effect of flexural loading on the performance of the fabricated composite materials is shown in graphs Fig. 3-8 three point bending test was employed to investigate this effect. Sisal and Roselle (hybrid) fiber composites are found to be withstanding more loading on flexural testing. The presence of sisal fiber in the reinforcement gives the strength. Even in the hybrid composites the slight reduction in the flexural behavior could be due to the sisal fiber presence. The presence of moisture in the composites reduces the flexural properties.

Since the absorption of moisture leads to the degradation of fibers matrix interface region creating poor stress transfer resulting in a reduction on the flexural strength. In the Roselle and Sisal (hybrid) fiber composites the percentage elongation is found to be increasing after immersing the components in to water Fig. 5. The reason could be the presence of water attack on the cellulose structure and allow the cellulose molecules to move smoothly. This nature is justified, where more percentage elongation could be observed for the Sisal and Roselle (hybrid) fiber composites which exhibit ductile nature of fracture due to the presence of sisal fibers. Sisal and banana (hybrid) and Roselle and banana (hybrid) fiber composites, on loading condition, showed a brittle like failure (less in \% of elongation, Fig. 3 and 4 ). where, Fr-Flexural rigidity. 


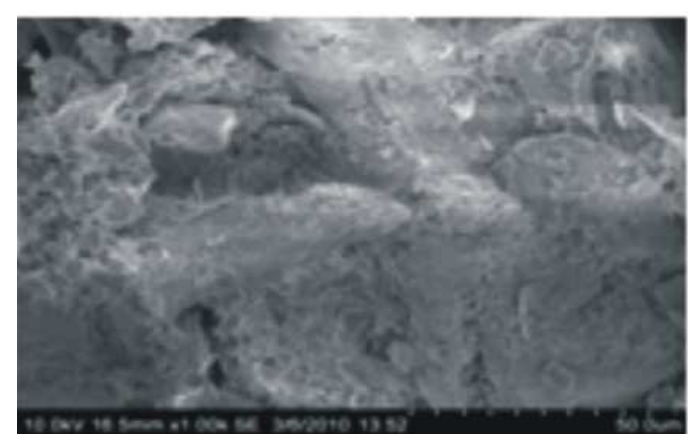

(a)

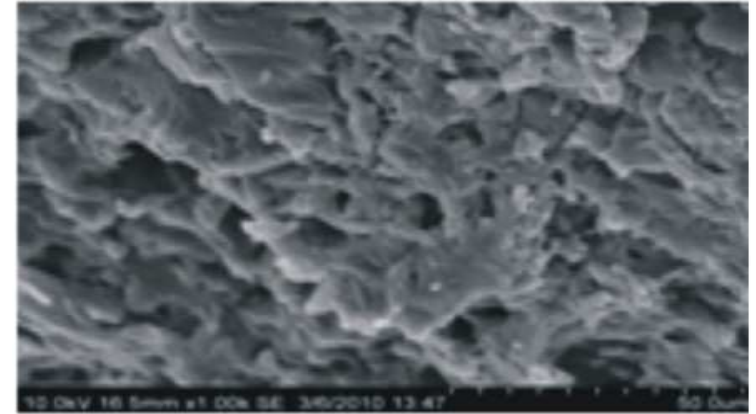

(b)

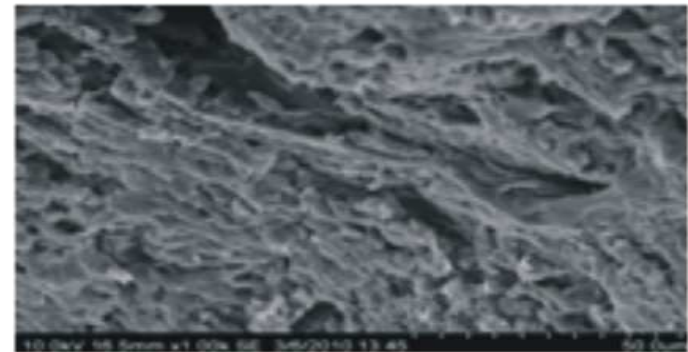

(c)

Fig. 1. (a) SEM of Sisal and banana (hybrid) with moisture (b) SEM of Roselle and banana (hybrid) with moisture (c) SEM of Roselle and sisal (hybrid) with moisture

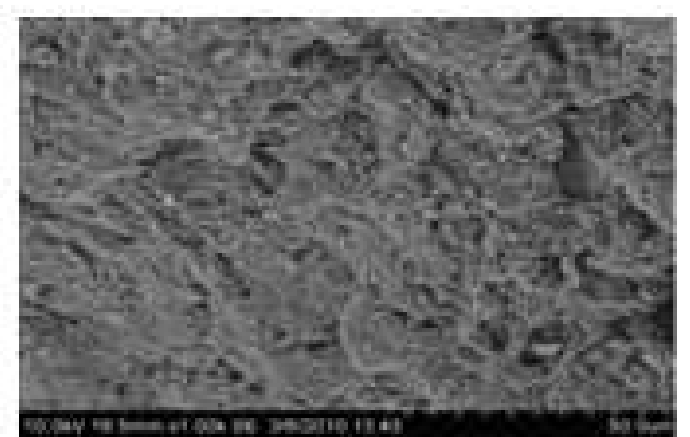

(a)

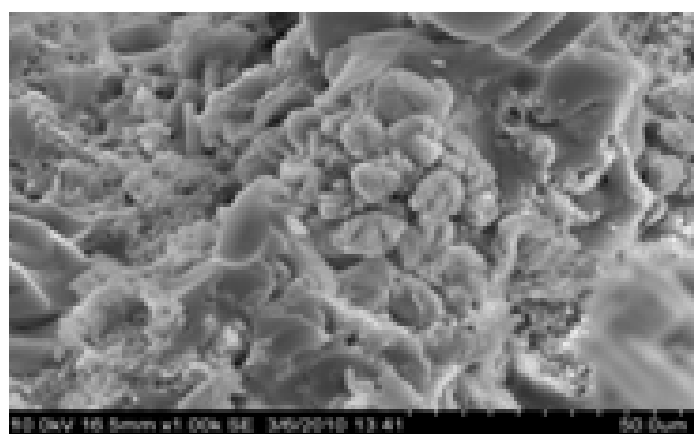

(b)

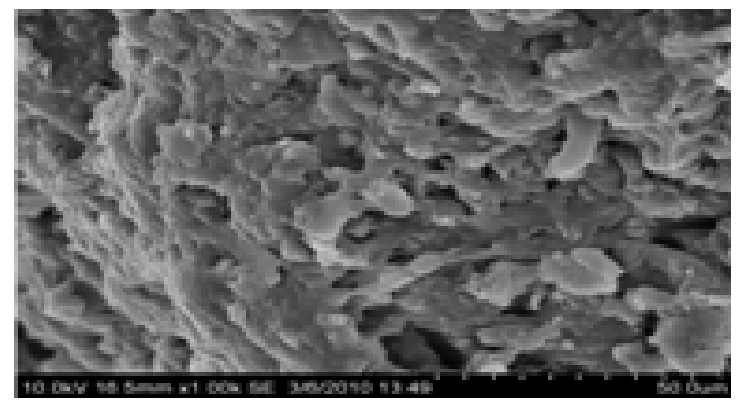

(c)

Fig. 2. (a) SEM of Sisal and banana (hybrid) without moisture (b) SEM of Roselle and banana (hybrid) without moisture (c) SEM of Roselle and sisal (hybrid) without moisture 
Chandramohan, D. et al. / American Journal of Applied Sciences 11 (4): 623-630, 2014

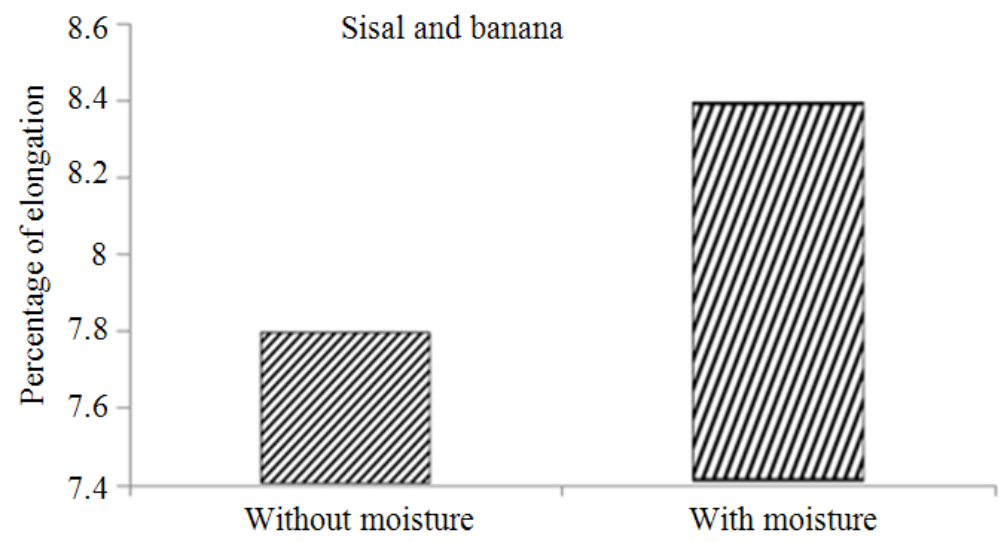

Fig. 3. Comparison of Sisal and Banana (hybrid) in with and without moisture

Rosellel and banana

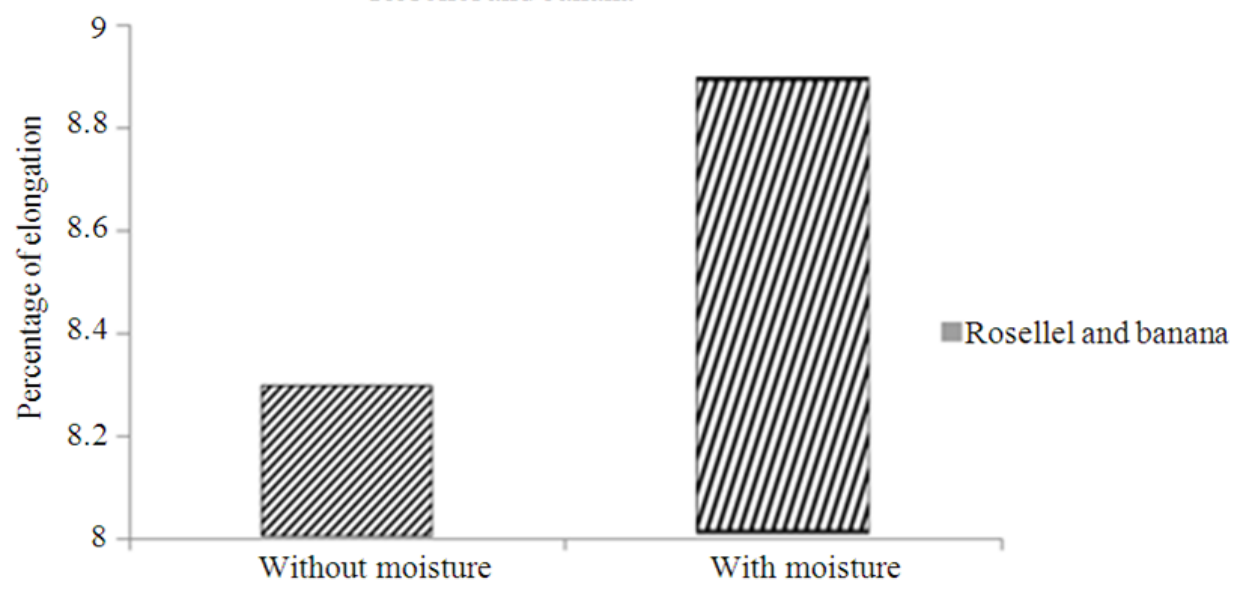

Fig. 4. Comparison of roselle and banana (hybrid) in with and without moisture

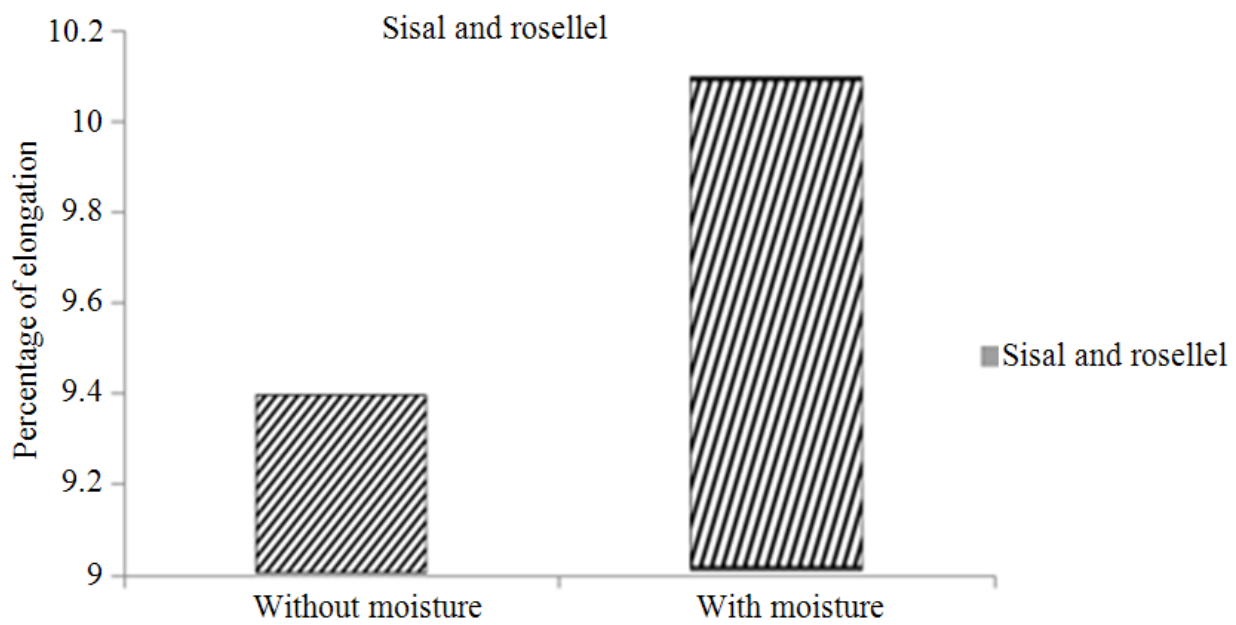

Fig. 5. Comparison of sisal and roselle (hybrid) in with and without moisture 
Chandramohan, D. et al. / American Journal of Applied Sciences 11 (4): 623-630, 2014

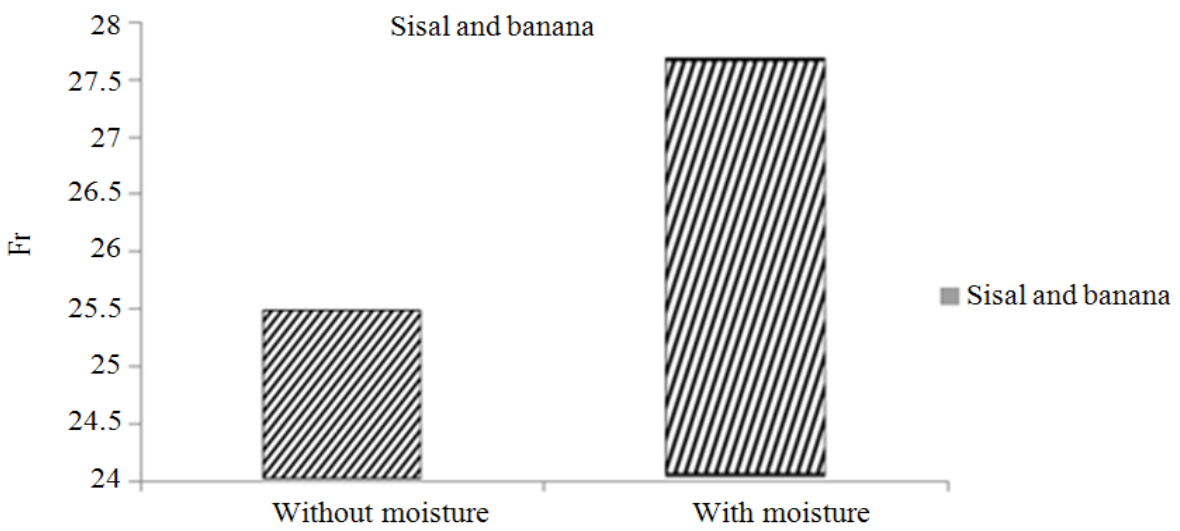

Fig. 6. Comparison of sisal and banana (hybrid) in with and without moisture

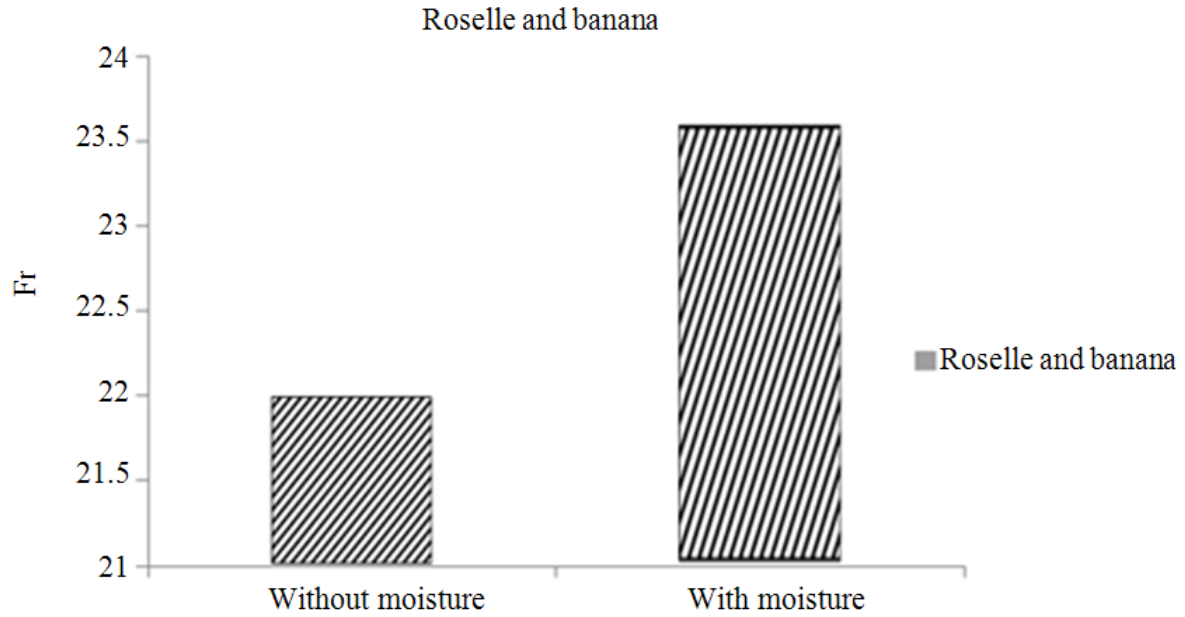

Fig. 7. Comparison of roselle and banana (hybrid) in with and without moisture

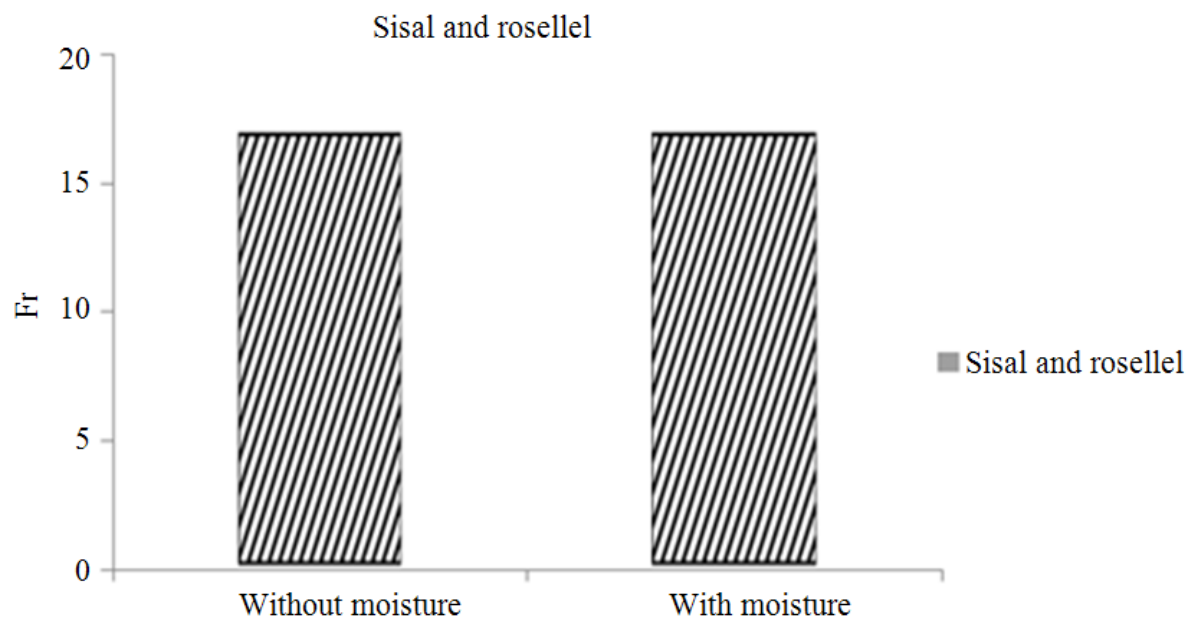

Fig. 8. Comparison of sisal and roselle (hybrid) in with and without moisture 


\section{CONCLUSION}

The stress analysis of humerus bone and fixation of plate for the fractured bone has been carried out with stainless steel, cobalt chrome, titanium, zirconium, Roselle and sisal (hybrid), Sisal and banana (hybrid) and Roselle and banana (hybrid). After plate fixation on humerus bone, the stress induced on the bone with plate and without plate is calculated both manually and using ANSYS software.

After determining the material properties of natural fiber-reinforced epoxy composite using six different tool materials and geometrices by using flexural rigidity test. The hybrid composites showed comparatively better performance, as evidenced by the micrographs taken for the fractured sisal, banana, roselle and hybrid composites. The presence of moisture in the composites reduces the flexural properties. The absorption of moisture leads to the degradation of fibers matrix interface region creating poor stress transfer, resulting in a reduction on the flexural strength. Both in the banana and sisal fiber composites, the percentage elongation are found to be increasing after immersing the components into water. The reason could be the presence of water attack on the cellulose structure, allowing the cellulose molecules to move smoothly. Hence, for the applications where flexural loading conditions are dominating, sisal and roselle composites could be selected. A result from material testing, mechanical testing and ANSYS this research work concluded that sisal and roselle (hybrid) is one of the best material. In future, this plate material can be externally coated with calcium phosphate and Hydroxy Apatite (hybrid) composite. Furthermore, this plate material can be used for internal fixation and also external fixation in fractured bones in human body. The most important point that researchers have to have in mind is that these steps taken will help humans to develop and have a more pleasant life.

\section{ACKNOWLEDGEMENT}

The researchers wish to thankfully acknowledge the Management of Vel Tech, Avadi, Chennai for their constant encouragement and support.

\section{REFERENCES}

Abrao, A.M., P.E. Faria, J.C. Campos Rubio, P. Reis and J.P. Davim, 2006. Drilling of fiber reinforced plastics: A review. J. Mater. Process. Technol., 186: 1-7. DOI: 10.1016/j.jmatprotec.2006.11.146
Baixauli, 1995. Carbon fiber composite bone plates for fixation of forearm fractures. J. Bone Joint Surg., 77: 227-227.

Blazewicz, J., K.H. Ecker, E. Pesch, G. Schmidt and J. Weglarz, 2007. Handbook on Scheduling: From Theory to Applications. 1st Edn., Springer, Berlin, ISBN-10: 3540322205, pp: 659.

Boeree, N.R., J. Dove, J.J. Copper, J. Knowles and G.W. Hastings, 1993. Development of a degradable composite for orthopaedic use: Mechanical evaluation of an hydroxyapatite-polyhydroxybutyrate composite material. Biomaterials, 14: 793-796. DOI: 10.1016/0142-9612(93)90046-5

Chandramohan, D. and K. Marimuthu, 2011. Contribution of biomaterials to orthopaedics as bone implants-a review. Proc. Int. J. Mater. Sci., 5: 445463.

Chandramohan, D., K. Marimuthu, S. Rajesh and M. Ravikumar, 2010. Applications of CT/CAD/RPT in the futurestic development of orthopedics and fabrication of plate and screw material from natural fiber particle reinforced composites for humerus bone fixation-a future drift. Proc. Malaysian J. Educ. Technol., 10: 73-81.

Charvet, J.L., 2000. Mechanical and fracture behavior of a fibre-reinforced bioabsorbable material for orthopaedic applications. J. Mater. Sci. Mater. Med., 11: 101-109. DOI: 10.1023/A:1008945017668

Clemons, C.M. and D.F. Caulfield, 1994. Natural fibers Sage. J. Reinforced Plast. Compos.

Fenner, R., 1996. High strength partially absorbable composites produced by sintering method for internal bone fixation. Proceedings of the Transaction of 5th World Biomaterials Congress, (BC' 96), Toronto, Canada, pp: 440-440.

Ganesh, V., 2005. Biomechanics of bonefracture fixation by stiffness-graded plates in comparison with stainlesssteel plates. BioMed. Eng. OnLine, 4: 4646. DOI: $10.1186 / 1475-925 X-4-46$

Joseph, K., R. Dias, T. Filho, B. James and S. Thomas et al., 1999. A review on sisal fiber reinforced polymer. Rev. Brasil. Eng. Agric. Ambiental, 3: 367-379.

Navarro, M., 2008. Biomaterials in orthopaedics. J. Royal Soc. Interface, 5: 1137-1158. DOI: 10.1098/rsif.2008.0151

Ramakrishna, K., 2004. Design of fracture fixation plate for necessary and sufficient bone stress shielding. JSME Int. J., Series C: Mechanical Syst. Mach. Elements Manuf., 47: 1086-1094. DOI: $10.1299 /$ jsmec.47.1086 